\title{
Assessment of Tractor Maintenance Practices of Tractor Operators at Ejura, Ghana
}

\author{
K. A. Aikins \\ Department of Agricultural \\ Engineering \\ Kwame Nkrumah University \\ of Science and Technology \\ Kumasi, Ghana \\ S. M. Ackah \\ Department of Agricultural \\ Engineering \\ Kwame Nkrumah University \\ of Science and Technology \\ Kumasi, Ghana
}

\author{
J. K. Afriyie \\ Department of Mechanical \\ Engineering \\ Kumasi Polytechnic \\ Kumasi, Ghana
}

\author{
I. N. Amanor \\ Department of Agricultural \\ Engineering \\ Kwame Nkrumah University \\ of Science and Technology \\ Kumasi, Ghana
}

\author{
E. Y. H. Bobobee \\ Department of Agricultural \\ Engineering \\ Kwame Nkrumah University \\ of Science and Technology \\ Kumasi, Ghana
}

\begin{abstract}
Tractors are very expensive and complex machines, hence they need to be well operated and maintained so as to preserve their service life and maximise their profitability. A survey involving 101 tractor operators was conducted at Ejura in the EjuraSekyedumasi District of the Ashanti Region of Ghana to assess their expertise in tractor operation and maintenance and their attitudes towards recommended maintenance practices. It was revealed that $62 \%$ of the operators have no formal training in tractor operation while $60 \%$ of them have had some sort of training in tractor maintenance. Tillage operations, which are the most strenuous operations, are the major operations carried out with tractors at Ejura as they represent $97 \%$ of the responses. Generally, the operators are mindful of lubrication practices such as oil change and greasing, and the general cleanliness of their tractors and their components. However, about $78 \%$ of them do not have their hour metres in working condition and therefore it cannot be guaranteed that their frequency of oil change and greasing are according to manufacturer's recommendations. Also, $97 \%$ of them store their tractors in the open space which exposes them to environmental conditions that cause metal parts to rust. Only about $25 \%$ of the operators are in possession of manufacturer's maintenance instructions out of which $80 \%$ adhere to the instructions in maintaining their tractors. As majority of them do not have their hour metres and thermostats operational, it could be said that operators' attitudes toward recommended maintenance operations are not appropriate.
\end{abstract}

Keywords: Tractor, tractor operators, operation, maintenance, daily checks

\section{INTRODUCTION}

Low level of agricultural mechanisation inhibits agricultural production and threatens food security (Alabadan and Yusuf, 2010). In Ghana, most farmers are small holders who make use of hand tools and implements which involve drudgery and places severe limitations on the size of land that can be cultivated. The use of hand tools reduces timeliness of farm operations and limits the effectiveness of essential operations such as cultivation and weeding, thereby reducing crop yield (Sims and Kienzle, 2006). Hence, mechanising agriculture through the adoption and appropriate use of the farm tractor and its related implements is necessary to boost productivity of land and labour, while reducing drudgery and improving timeliness of agricultural operations (FAO, 2008).

However, deterioration, that is, depreciation and functional deviation of these machinery commences immediately after they are manufactured which results in a reduction in their output (Bello, 2013). This is due to their exposure to environmental and working conditions. In an agricultural enterprise, this deterioration results in reductions in crop returns and consequently profit. This makes the correct operation and maintenance of farm machinery indispensable practices if their maximum capacities are to be realized (Ali, 2014). Proper maintenance carried out at the right time saves the farmer cost of replacement parts and repair, and reduces the incidence of unexpected breakdowns and down times (Sullivan et al., 2007). However, most operators in Ghana lack the appropriate skills to operate and maintain these machines effectively (Aikins and Kyere, 2012). For this reason, tractors in Ghana and other parts of Africa generally break down soon after their acquisition. Fonteh (2010) revealed that more than $20 \%$ of tractors imported into Mali were out of operation after a year due to poor maintenance. This study was therefore aimed at examining the expertise of tractor operators on tractor operation and maintenance and to assess their attitudes towards recommended maintenance practices.

\section{MATERIALS AND METHODS}

\subsection{The Study Area}

The survey was conducted at Ejura in the Ejura-Sekyedumasi District in the Ashanti Region of Ghana. Ejura is located within longitudes $1^{\circ} 5^{\prime} \mathrm{W}$ and $1^{\circ} 39^{\prime} \mathrm{W}$ and latitudes $7^{\circ} 9^{\prime} \mathrm{N}$ and $7^{\circ} 36^{\prime} \mathrm{N}$ at an altitude of about $228 \mathrm{~m}$. The district is found within the transitional zones of the semi-deciduous 
forest and Guinea Savannah zones of Ghana. The southern part of the district experiences bi-modal rainfall while the northern part experiences uni-modal rainfall pattern with the main rainy season being from April to November. Annual rainfall ranges between $1,200 \mathrm{~mm}$ and $1,500 \mathrm{~mm}$. The land has flat and undulating topography and the soils in the district also have good water-holding capacity which make them very easy to work, making the place suitable for mechanised farming. Ejura therefore boasts of the highest population of farm tractors in Ghana. The soils range from sandy loam to clay and are suitable for growing crops such as maize, millet, groundnuts, cowpea, guinea corns, yams, cassava, gardeneggs and tomatoes (Taiwo and Kumi, 2015; Aikins and Kyere, 2012; Kemausuor et al., 2011).

\subsection{Data Collection and Analyses}

A questionnaire was prepared and used to collect data from 101 tractor operators at Ejura on their personal information, their expertise in tractor operation and maintenance, types of tractors and what they are used for, their general maintenance practices, lubrication and greasing and maintenance of the engine and its systems. The questionnaire was administered in March, 2015. Data collected were summarised and analysed using the Statistical Package for Social Scientists (SPSS) and results are displayed using descriptive charts and frequency tables.

\section{RESULTS AND DISCUSSION 3.1 Personal Information}

Responses to the questionnaire indicate that all tractor operators at Ejura are males. As shown in Table 1, $4 \%$ of the tractor operators were below 20 years of age. $9.9 \%$ of them were between 20 and 29 years, $45.5 \%$ were between 30 and 39 years, $23.8 \%$ of them were within the age range of $40-49$ and $16.8 \%$ were 50 years and above. In all, $83.2 \%$ of the operators were below 50 years of age indicating considerable involvement of the youth in tractor operation at Ejura.

Table 1. Age of tractor operators

\begin{tabular}{|l|c|c|}
\hline Age (Years) & Frequency & Percentage \\
\hline Below 20 & 4 & 4.0 \\
\hline From 20-29 & 10 & 9.9 \\
\hline From 30-39 & 46 & 45.5 \\
\hline From 40-49 & 24 & 23.8 \\
\hline 50 and above & 17 & 16.8 \\
\hline Total & 101 & 100.0 \\
\hline
\end{tabular}

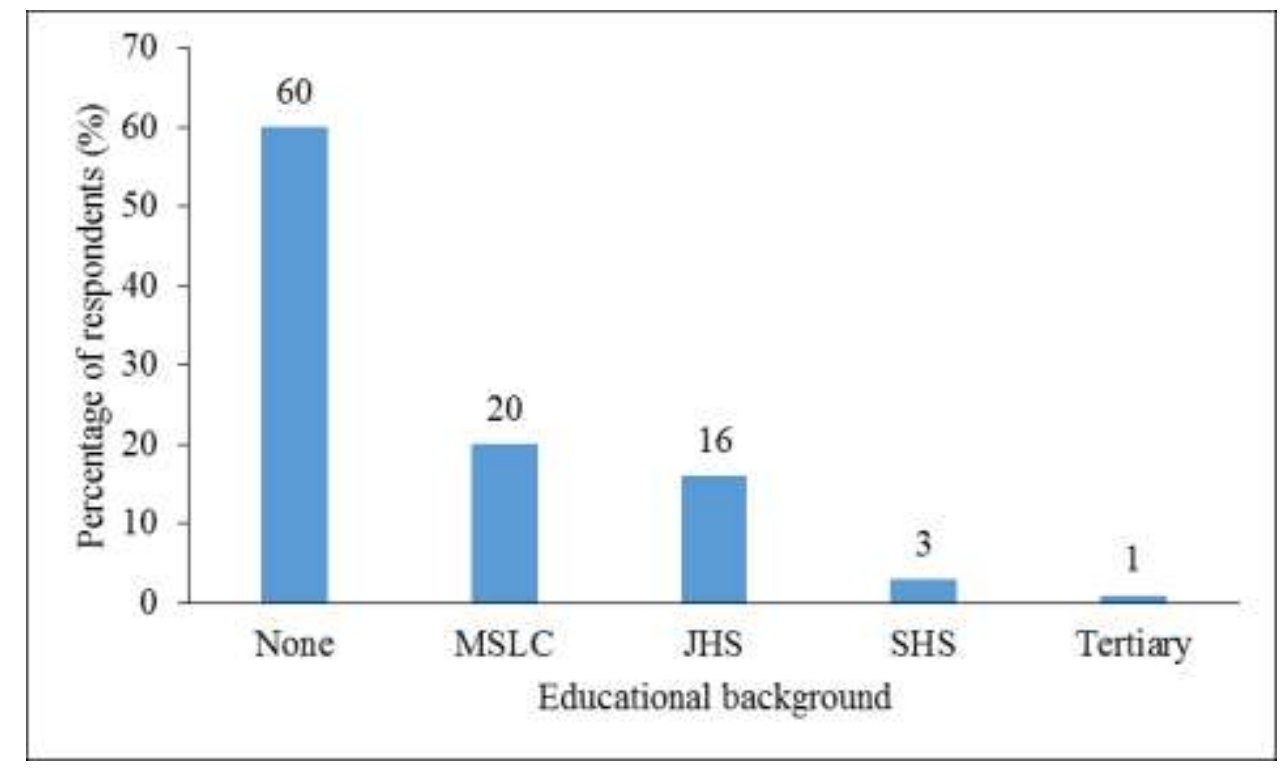

Figure 1. Educational background of tractor operators

Figure 1 also shows the educational background of tractor operators at Ejura. Those who have no formal education constitute $60 \%$ of the respondents. About $26 \%$ of the respondents have only basic education, that is, Junior High School (JHS) leavers and Middle School Leaving Certificate (MSLC) holders while 3\% are Senior High School (SHS) graduates and $1 \%$ have up to tertiary level education. Education is necessity if one is to operate and maintain a tractor effectively since it will enable the tractor operator to read the operators' manual and understand how the tractor is used. Majority of these operators having no formal education implies they do not have the ability to read and understand the operators' manual which impairs their effectiveness in undertaking recommended operation and maintenance practices putting themselves and the tractor at risk (Aikins and Kyere, 2012, Adjei et al., 2003). 


\subsection{Expertise of Tractor Operators in Operation and Maintenance}

\subsubsection{Training in tractor operation}

Figure 2 shows how the tractor operators had their training in tractor operation. Responses from the interview show that $62 \%$ had their training through apprenticeship under older operators, $33 \%$ through operator training programmes organised by tractor operators' associations and 5\% through an association of mechanics who are as well able to operate tractors. These associations have been encouraged by the government to help equip tractor owners and operators with knowledge in tractor operation and maintenance. The low level of education of tractor operators at Ejura as indicated in Figure 1 could be attributed to an early engagement of the youth in tractor operation through apprenticeship, which could be a discouraging factor to formal education. The method of apprenticeship training in tractor operation depicted in Figure 2 is suggestive of this observation.

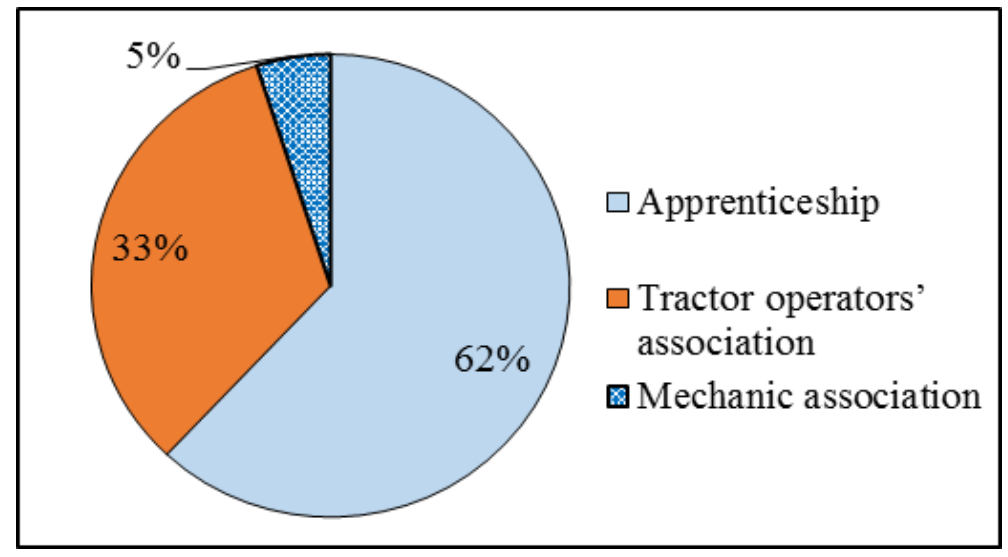

Figure 2. Training in tractor operation

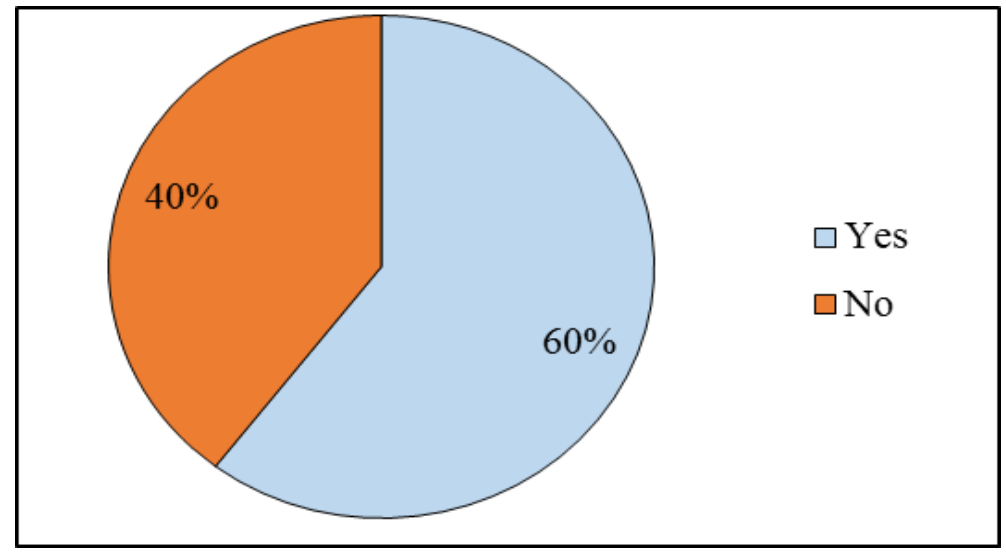

Figure 3. Training in tractor maintenance

\subsubsection{Training in tractor maintenance}

It can be seen from Figure 3 that $60 \%$ of the operators interviewed have had some form of training in tractor maintenance. However, about $40 \%$ did not have any form of training in tractor maintenance. Training in maintenance enables the tractor operator to effectively maintain his tractor which in turn increases the lifespan of the tractor (Adjei et al., 2003).

\subsection{Tractors and Their Uses}

\subsubsection{Make of farm tractors}

Responses from the tractor operators interviewed show that the most common make of tractor found at Ejura is Massey Ferguson, representing $75.2 \%$ of tractors used at Ejura, as shown in Table 2. This confirms the finding of Aikins and Kyere (2012) which indicated that the most common tractor make used at Ejura was Massey Ferguson.
Table 2. Tractor makes

\begin{tabular}{|l|c|c|}
\hline Tractor make & Frequency & Percentage (\%) \\
\hline Massey Ferguson & 76 & 75.2 \\
\hline Ford & 19 & 18.8 \\
\hline Farmtrac & 1 & 1.0 \\
\hline Mahindra & 3 & 3.0 \\
\hline Landini & 2 & 2.0 \\
\hline Total & 101 & 100.0 \\
\hline
\end{tabular}




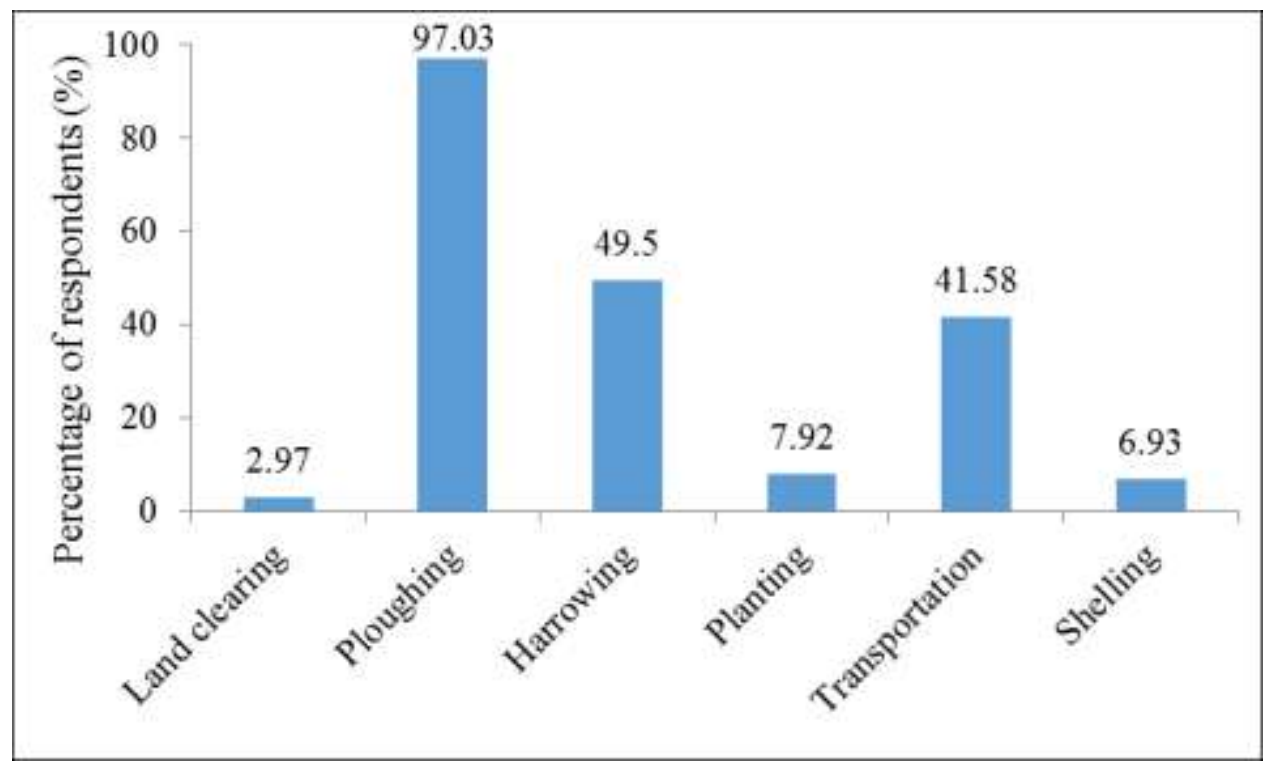

Figure 4. Uses of tractors at Ejura

\subsubsection{Uses of tractors at Ejura}

Figure 4 depicts the tasks operators at Ejura use their tractors to perform. About 3\% use their tractors in land clearing operations, $97 \%$ use theirs for ploughing, $49.5 \%$ use theirs for harrowing, $7.9 \%$ use theirs for planting, $41.6 \%$ also use theirs for transportation purposes and $6.9 \%$ use theirs for shelling. How often a tractor should be maintained or serviced also depends on the kind of tasks it is used to perform. Almost all the operators use their tractors, among other operations, for land preparation such as ploughing and harrowing. Generally, however, land preparation is characterised by high draught requirement which exposes tractor parts and implements to higher levels of stress. Thus, the tractors need to be adequately maintained in order to reduce their rate of deterioration and ensure longevity (Sims and Kienzle, 2006; Paman et al., 2012).

Table 3. Responses on the possession of and adherence to operators' manual

\begin{tabular}{|l|l|l|l|l|}
\hline Response & \multicolumn{2}{|c|}{ Possession of operators' manual } & \multicolumn{2}{c|}{ Adherence to operators' manual } \\
\hline & Frequency & Percentage & Frequency & Percentage \\
\hline Yes & 25 & 24.8 & 20 & 80 \\
\hline No & 76 & 75.2 & 5 & 20 \\
\hline
\end{tabular}

\subsubsection{Possession of and adherence to tractor operators' manual}

Table 3 displays the numbers of tractor operators who possess operators' manual and the number that adhere to its recommendations. Just about $25 \%$ have operators' manual. Eighty percent out of this $25 \%$ adhere to the manual. This means that only $20 \%$ of those interviewed adhere to tractor operators' manual. This low percentage of adherence to manual could be attributable to the low level of education depicted in Figure 1 and confirms earlier findings by Aikins and Kyere (2012).

The tractor operators' manual is a very important document which enables an adherent operator to gain proficiency in tractor operation, develop safe operation practices and evaluate his techniques periodically to eliminate unsafe habits (Aikins and Kyere, 2012). Not adhering to the operators' manual can cause serious hazards resulting in fatal accidents and unexpected breakdowns (Anin, 2014).

\subsubsection{Condition of hour metre}

Table 4 presents responses on the condition of the hour metres of the tractors of the operators interviewed. Only $21.8 \%$ of the respondents have their hour metres in working condition. This shows that they do not see the importance of the hour metre and so do not make any decisions based on its readings. The hour metre records the hours the engine runs. It helps one to know when to check the inflation and conditions of tyres, tighten loose bolts and nuts, clean air filters and also change the engine oil. When one does not have the hour metre in working condition, it becomes difficult to accurately tell when to service or maintain certain parts of the tractor. This could also be a contributing factor to the low level of adherence to operators' manual presented in Table 3 This difficulty to determine the time for maintaining certain parts can lead to the deterioration of those parts, eventually resulting in breakdown (Bello, 2013).

Table 4. Condition of hour metre

\begin{tabular}{|l|c|c|}
\hline $\begin{array}{l}\text { Condition of } \\
\text { hour metre }\end{array}$ & Frequency & Percentage \\
\hline Working & 22 & 21.8 \\
\hline Not working & 79 & 78.2 \\
\hline Total & 101 & 100.0 \\
\hline
\end{tabular}




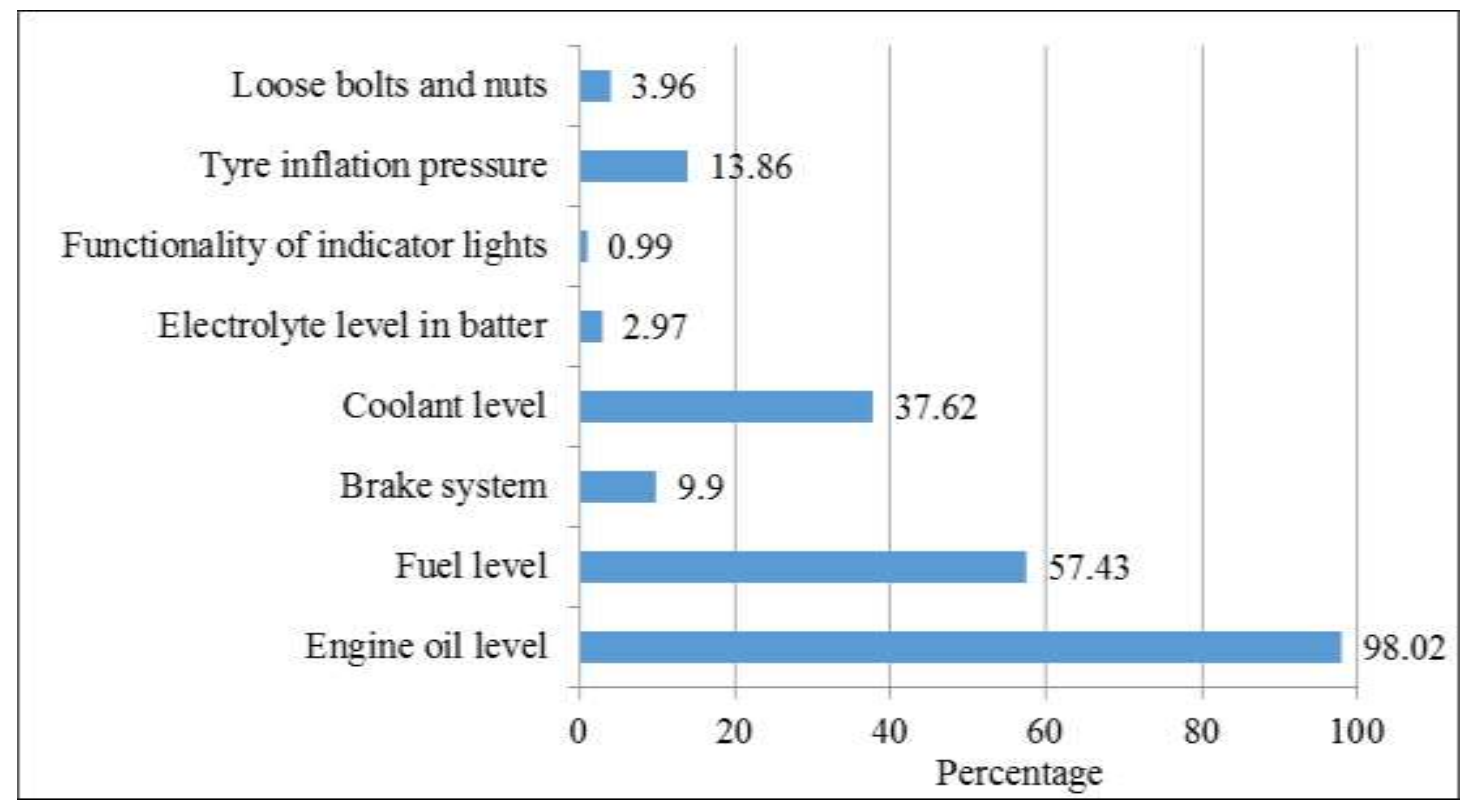

Figure 5. Responses on daily checks carried out by tractor operators

\subsection{Maintenance Practices}

\subsubsection{Daily checks}

Figure 5 shows the daily checks performed by the tractor operators that took part in the survey. Approximately $4 \%$ of the tractor operators check for loose bolts and nuts daily. About $14 \%$ check their tyre inflation pressure. Almost $1 \%$ check the functionality of their indicator lights, $3 \%$ check the electrolyte level of their batteries, about $38 \%$ check their coolant level, $10 \%$ check their brake system, $57 \%$ check their fuel tank level and approximately $98 \%$ check their engine oil level.

Generally, the chart shows that the operators are mindful of lubrication practices such as oil change. These practices help to keep the tractor in good condition. For instance, regular tightening of loose bolts and nuts will help prevent any loose part of the tractor from coming off while in operation. Checking of tyre inflation pressure, electrolyte level in the battery or fuel tank level can also help protect the tractor against unforeseen breakdowns on the farm and project the soil from excessive compaction (Bello, 2013; Harshman et al., 2004).

\subsubsection{Record keeping}

Table 5, shows the percentage of tractor operators who keep records and those who do not. It could be seen that only $20.8 \%$ of them keep records on the maintenance of their tractor, and this may be attributed to the low level of education as shown in Figure 1. Record keeping enables an operator to know which parts of the tractor was last serviced and which parts need servicing. It is upon this evidence that decisions are made for future actions (Clifton, 1982; Petrov and Bisnovaty, 1986).

\section{Table 5. Records keeping}

\begin{tabular}{|l|c|c|}
\hline Record keeping & Frequency & Percentage \\
\hline Yes & 21 & 20.8 \\
\hline No & 80 & 79.2 \\
\hline Total & 101 & 100.0 \\
\hline
\end{tabular}

\subsubsection{Washing/Cleaning of the tractor}

Figure 6 illustrates how frequently tractor operators at Ejura wash or clean their tractors. It can be seen that a sizable majority $(86 \%)$ prefer to wash their tractors once a week, while $9 \%$ wash theirs more frequently. About $4 \%$ of the operators wash their tractors once every two weeks and the other $1 \%$ wash theirs only when they become dirty.Regular cleaning or washing of the tractor is very important because it will enable the tractor to last longer. Leaving soil and plant materials to decay on tractor parts causes corrosion of such parts. Also, oily steps and dirty safety decals on the tractor expose the operator to danger (Jarrett, 1995; University of Florida, 1998; Utah State University Cooperative Extension, 1995). Since about $95 \%$ of the tractor operators wash their tractors at least once in a week, it shows that they are generally mindful of the cleanliness of their tractors. 


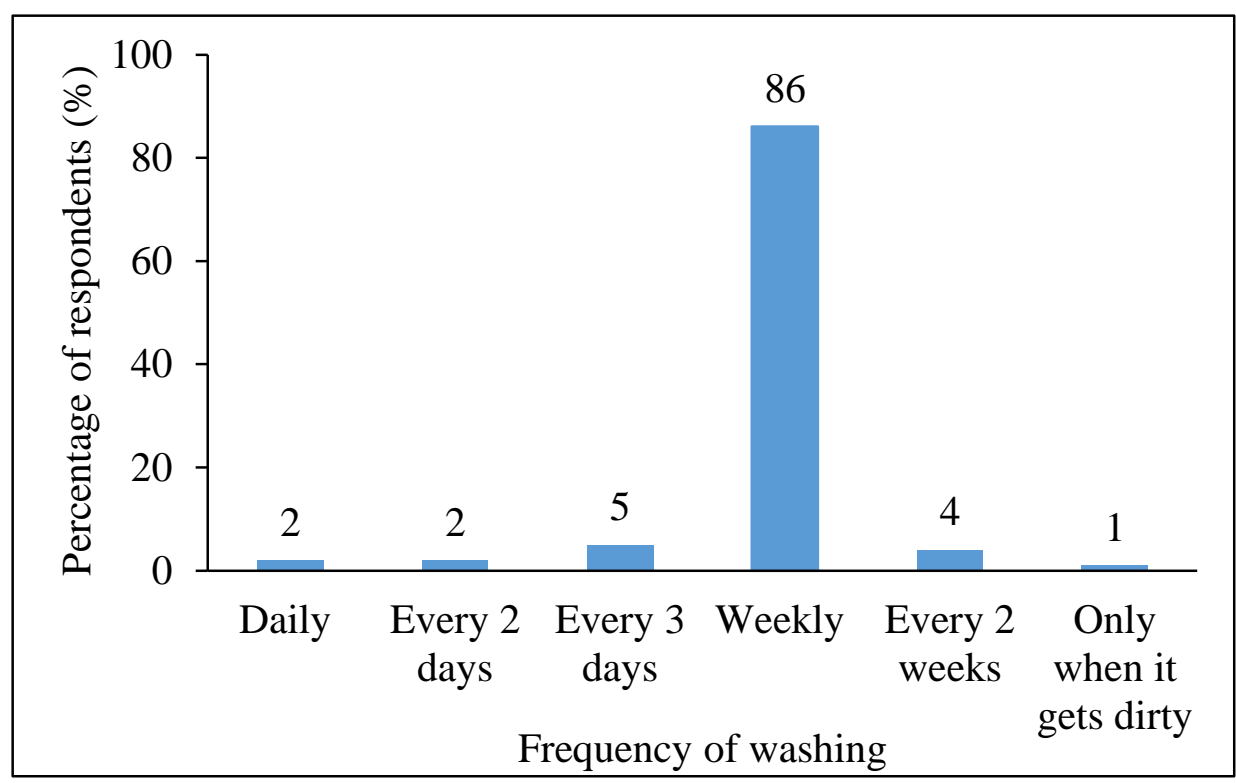

Figure 6. Washing of tractor

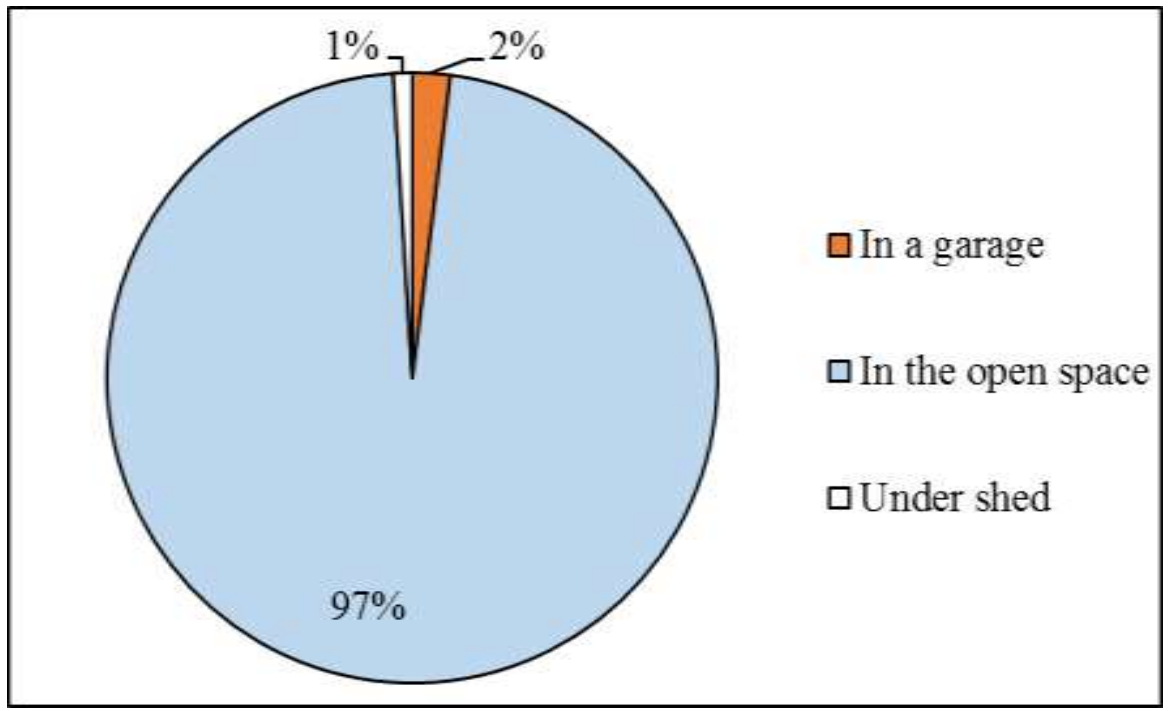

Figure 7. Tractor housing

\subsubsection{Tractor housing}

Figure 7 shows where tractors are kept after each day's work. Only $2 \%$ keep their tractors in a garage. $1 \%$ keep theirs under a shed but the majority which is $97 \%$ leave their tractors in the open space. Leaving the tractor in the open space will expose it to harsh environmental conditions such as wind and rain which will lead to rusting. Provision of shelter for the tractor will therefore protect it from theft and environmental conditions which will result in longer life and improved appearance (Aikins and Kyere, 2012; North Central Regional Farm Structures Coordinating Committee, Subcommittee on Machinery Storage and Farm Shops, 1952).

\subsection{Lubrication and Greasing of Body Parts}

3.5.1 Condition of oil pressure gauge

As shown in Figure 8, 85\% of the tractor operators have their oil pressure gauge in working condition whereas the remaining $15 \%$ do not. The oil pressure gauge indicates the oil pressure inside the engine. It determines when the tractor needs a top up of engine oil. $85 \%$ of the operators having their oil pressure gauge in working condition means majority of them see the importance of lubrication. Lubricating moving parts of the engine protects it from friction, wear and excessive heating (Bello, 2013). 
International Journal of Science and Engineering Applications Volume 5 Issue 5, 2016, ISSN-2319-7560 (Online)

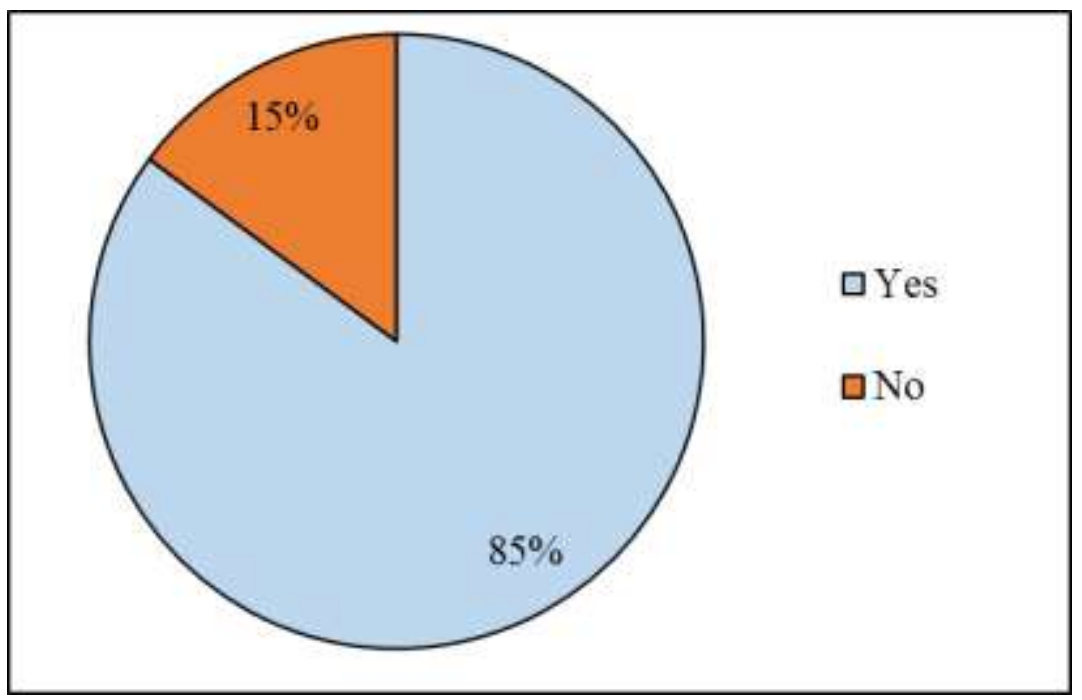

Figure 8 . Working condition of oil pressure gauge

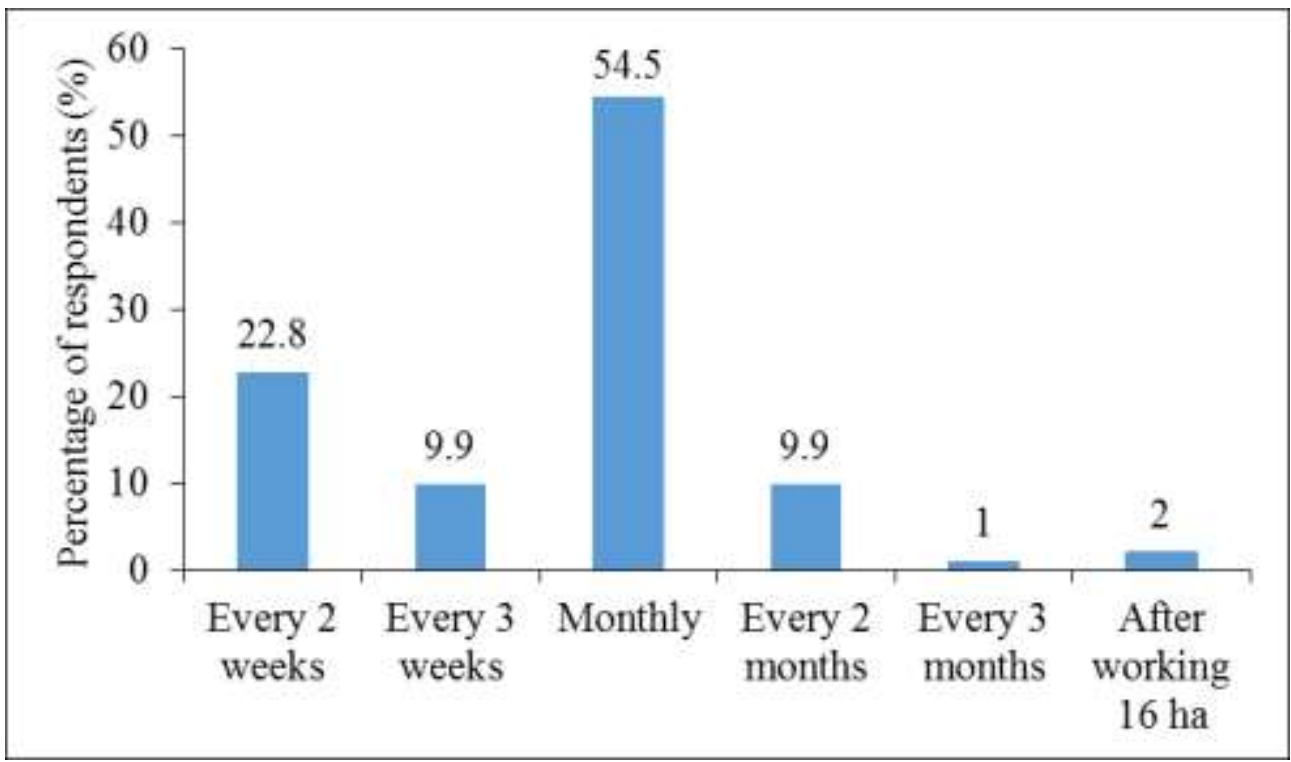

Figure 9. Frequency of changing engine oil 


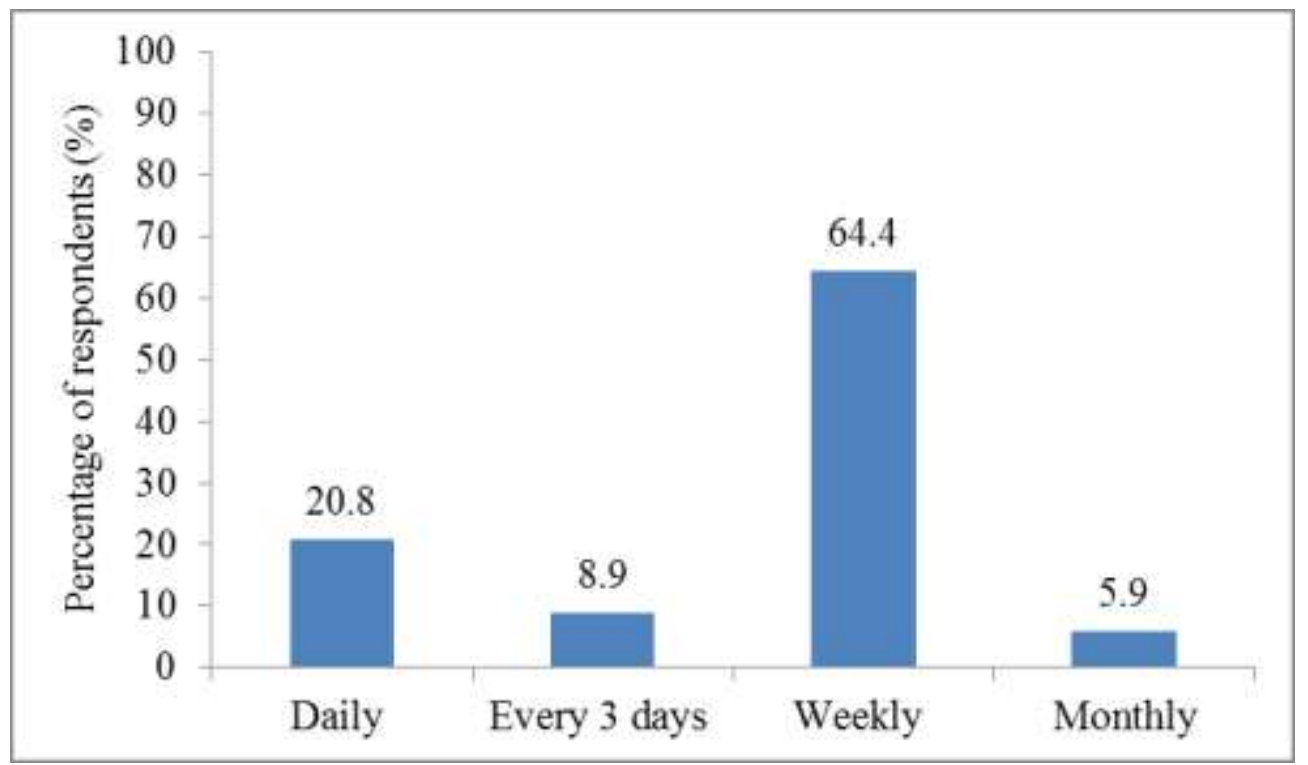

Figure 10. Frequency of greasing of tractor body parts

\begin{abstract}
3.5.2 Frequency of changing engine oil and greasing Figure 9 shows responses on how often the tractor operators change their engine oil. Approximately $23 \%$ change their engine oil once in every 2 weeks. $10 \%$ change theirs once in every 3 weeks, about $55 \%$ change theirs monthly, $10 \%$ also change theirs once in every 2 months, about $2 \%$ change theirs within every 3 months and 3\% change theirs after working 16 hectares. This shows that tractor operators at Ejura generally do not base their oil use period and oil change on the number of hours the engine is run. This buttresses the observation that about only $22 \%$ of the operators have their hour metres in operating condition.
\end{abstract}

Figure 10 shows how frequently the tractor operators grease their tractor body parts. About $20.8 \%$ grease their tractors daily, about $8.9 \%$ grease theirs once in every 3 days, $64.4 \%$ grease theirs weekly and $5.9 \%$ grease theirs monthly. This shows that the tractor operators are mindful of lubrication. Lubrication is very necessary since it reduces friction and enables the moving parts of the tractor to function smoothly to reduce wear and heat generation.

\subsection{Engine Systems}

\subsubsection{Overhauling}

It could be seen in Table 6 that $95 \%$ of the tractor operators that took part in the survey have performed an overhaul of their tractors' engines while 5\% have never performed an overhaul of their tractor engine yet. Most perform an overhaul once in every two years and usually as a result of the wearing off of their piston rings. The low level of adherence to maintenance manual could also be a course for that. Overhauling is a popular way of maintaining tractor engines and ensuring a problem free operation (Bello, 2013).

Table 6. Overhauling

\begin{tabular}{|l|c|c|}
\hline Overhauling & Frequency & Percentage \\
\hline Yes & 96 & 95.0 \\
\hline No & 5 & 5.0 \\
\hline Total & 101 & 100.0 \\
\hline
\end{tabular}

\subsubsection{Changing of fuel filter}

Figure 11 presents how often the tractor operators change their fuel filters. About $18.8 \%$ change theirs once in every 3 weeks, $51.5 \%$ change theirs monthly, $11.9 \%$ change theirs once in every 2 months and about $17.8 \%$ change theirs after changing the engine oil. The fuel filter is responsible for the removal of impurities from the fuel. Unfiltered fuel may contain several kinds of contamination such as dust particles, sediments, wax and rust caused by moisture in a steel tank. If these substances are not removed, they will cause rapid blockage and failure of the fuel pump and injectors. Fuel filters also help improve engine performance in the sense that the fewer contaminants there are in the fuel, the cleaner and more efficient the fuel combustion (Bello, 2013; Cummins Filtration Inc., 2010). 


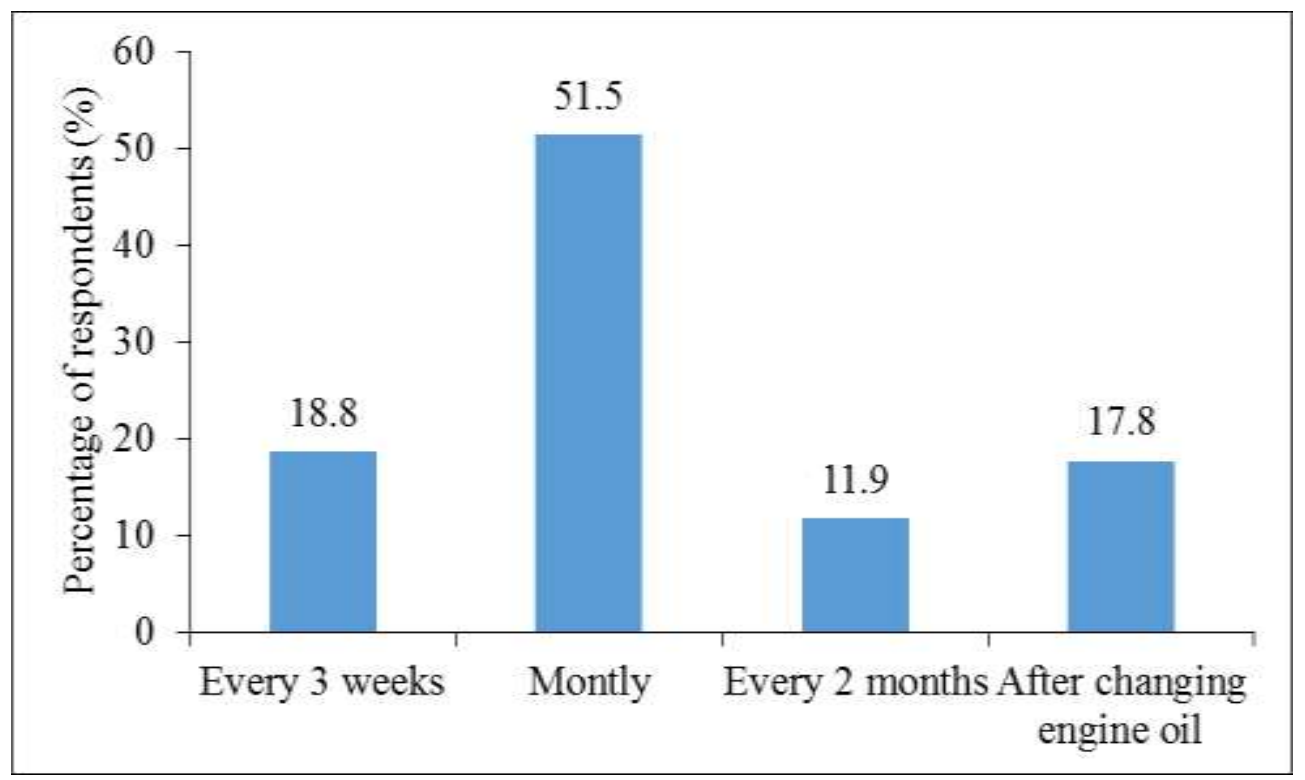

Figure 11. Changing of fuel filter

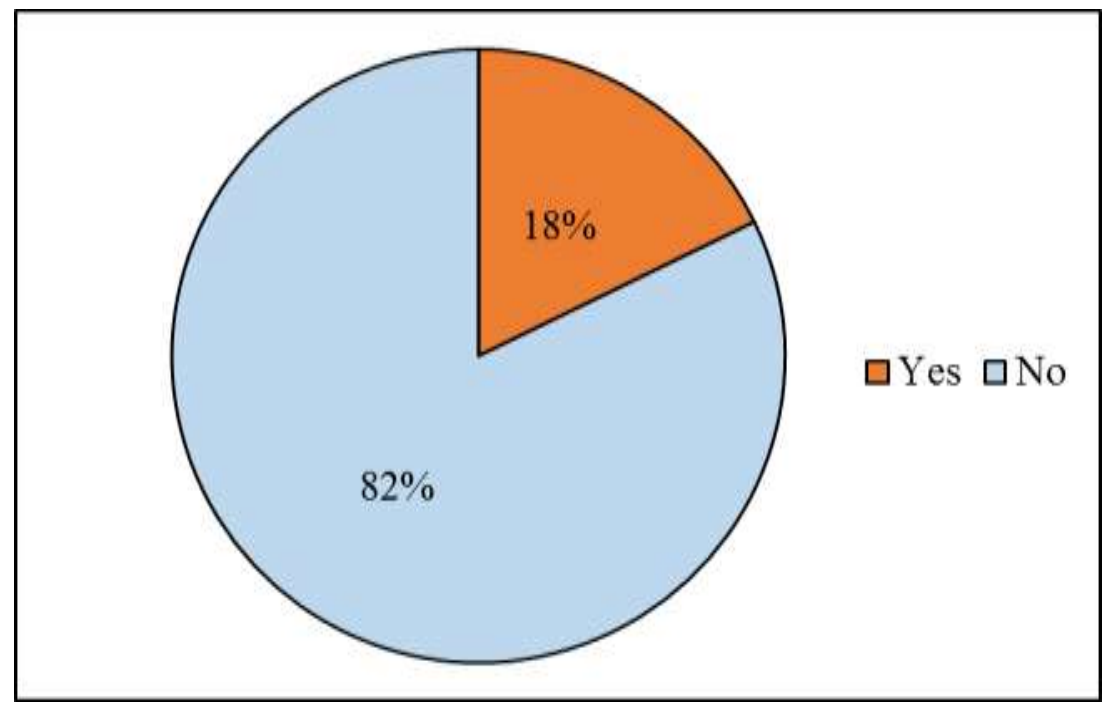

Figure 12. Working condition of thermostat

\subsubsection{Cooling system: Condition of thermostat}

Figure 12 represents responses of tractor operators on the condition of their engines' thermostats. Most of the operators, that is $82 \%$, have removed their thermostats from their tractors. Only $18 \%$ have theirs in working condition. This is due to a general perception that thermostats are not useful in tropical areas of the world which implies the operators do not appreciate the fact that thermostats regulate the temperature of an engine and protects it from overheating. The thermostat is however useful as it ensures a quick warm-up of engines to vaporise the combustion water, which can otherwise react with some sulphur impurities in the fuel to form sulphuric acid and corrode the inner parts of the engine.

\subsubsection{Electrical system: Cleaning of battery cables and} terminals

Figure 13 depicts how often the tractor operators interviewed clean their battery cables and terminals. About $98 \%$ of them clean their battery cables and terminals while the remaining $2 \%$ do not. Regular cleaning of battery cables and terminals will help prevent hard starting of the engine due to accumulation of dirt or corrosion (Bello, 2013; Paterson, 2009). 


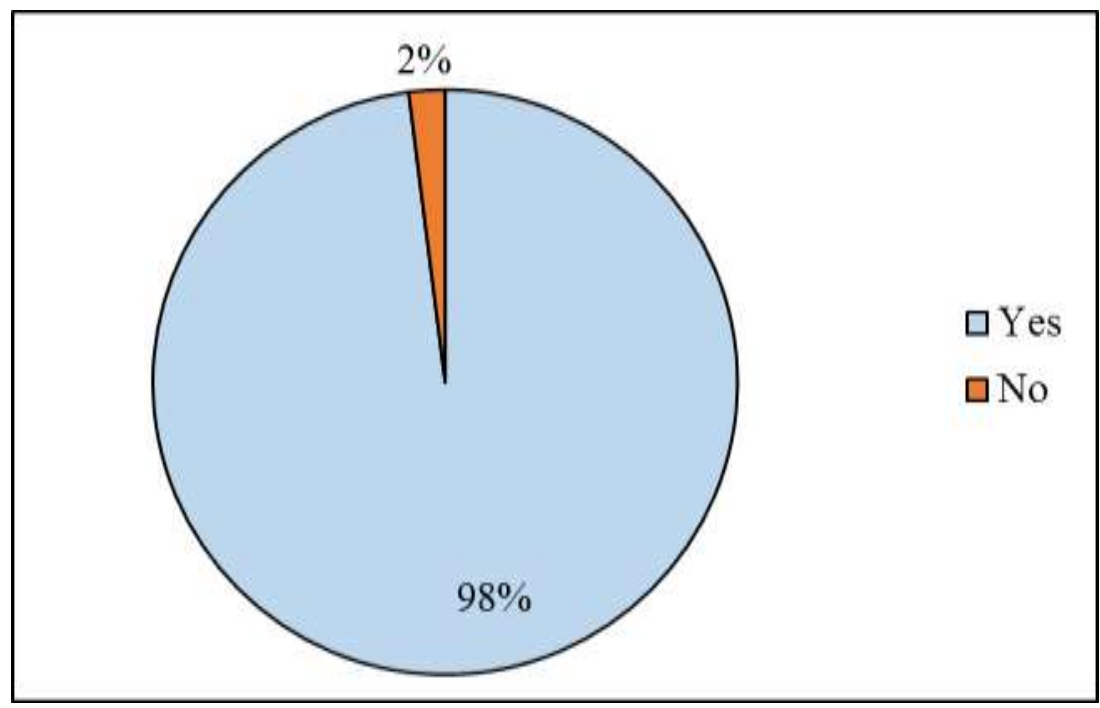

Figure 13. Cleaning of battery cables and terminals

\section{CONCLUSIONS}

Majority of tractor operators at Ejura have no formal education which implies that they do not have the ability to read and understand the operators' manual which impairs their effectiveness in undertaking recommended operation practices putting themselves and their tractors at risk. Most of these operators had their training in tractor operation through apprenticeship which means they have not been trained formally hence lack certain knowledge that will enable them to effectively operate and maintain the tractor. Almost all the operators use their tractors, among other operations, for tillage purposes such as ploughing which exposes tractor parts and implements to higher levels of stress since tillage operations are laborious.

Generally, it could be deduced that the operators are mindful of lubrication practices such as oil change and greasing, and the general cleanliness of their tractors and their components such as battery cables and terminals. However, only few of them possess and adhere to manufacturer's maintenance instructions. In addition, about $78 \%$ of the tractor operators at Ejura do not have their hour metres operational because they do not see the importance of the hour metre and hence do not make any decisions based on its readings. These observations imply that the operators' attitudes toward recommended maintenance operations are not appropriate.

The results also show that $97 \%$ of the tractor operators interviewed leave their tractors in the open space which exposes the tractors to environmental conditions such as wind and rainfall. This eventually leads to rusting of the tractor body parts. Also, $98 \%$ of the operators indicated they have uninstalled the thermostats on their engines, exposing the engine to the danger of damage through overheating and corrosion.

\section{ACKNOWLEDGMENTS}

The authors wish to express to express sincere gratitude to Mr. Boakye, an Extension Officer at the Ministry of Food and Agriculture, Ejura in the Ashanti Region of Ghana for facilitating the collection of data from the tractor operators.

\section{REFERENCES}

Adjei, E. O., Aikins, S. H. M., Boahen, P., Chand, K., Dev, I., Lu, M., Mkrtumyan, V., Samaraweera, S. D., Teklu, A. (2003). Combining Mechanisation with Conservation Agriculture in the Transitional Zone of Brong Ahafo Region, Ghana. International Centre for Development Oriented Research in Agriculture; Sedentary Farming Systems Project; CSIR-Soil Research Institue; Kwame Nkrumah University of Science and Technology.

Aikins, S. H. M., Kyere, J. B. (2012). A survey of Agricultural Tractor Operator's Background at Ejura, Ghana. Global Journal of Biology, Agriculture \& Health Sciences, vol.1 (1) 2012:1-6.

Alabadan, B. A. and Yusuf, Y. (2010). Tractor Hiring Schemes in Nigeria: A case study of Federal Capital Territory (FCT). African Journal of Agricultural Research. Vol. 8(47), pp. 5962-5966.

Ali, P. A. (2014). Assessments of Farm Tractor Maintenance Practices of Tractor Operators in Wenchi. BSc. Thesis, Department of Agricultural Engineering, Kwame Nkrumah University of Science and Technology, Kumasi, Ghana.

Anin, N. K., (2014). Assessment of Tractor Maintenance Practices of Tractor Operators in the Mampong Municipality. BSc. Thesis, Department of Agricultural Engineering, Kwame Nkrumah University of Science and Technology, Kumasi, Ghana.

Bello, S. R. (2013). Farm Tractor System Maintenance \& Operation. Published by Suite B. North Charleston, SC 29418 USA.

Clifton, R. H. (1982). Principle of Planned Maintenance. Edward Arnold (Publishers) Ltd. London.

Cummins Filtration Inc. (2010). Fuel Filtration Fact Sheet. Electronic document. Retrieved from: https://www.cumminsfiltration.com/pdfs/product_lit/americas _brochures/LT36179-GB.pdf. Accessed 14 March 2016.

FAO (2008). Agricultural Mechanisation in Africa...Time for Action. Food and Agriculture Organisation of the United Nations, Rome. 
Fonteh, M. F. (2010). Agricultural Mechanization in Mali and Ghana: strategies, experiences and lessons for sustained impacts. Agricultural and Food Engineering Working Document No.8. FAO, Rome.

Harshman, W. C., Yoder, A. M., Hilton, K. W., Murphy, D. J. (2004). Preventative Maintenance and Pre-Operation Checks. HOSTA Task Sheet 4.6, National Safe Tractor and Machinery Operation Program.

Jarrett, V. H. (1995). Machinery Storage-Put it Away Clean, Dry and Lubricated. Farm Machinery Fact Sheet FM-17, Utah State University, Logan, Utah.

Kemausuor, F., Dwamena, E., Bart-Plange, A., Kyei-Baffour, N. (2011). Farmers' Perception of Climate Change in the Ejura-Sekyedumase District of Ghana. ARPN Journal of Agricultural and Biological Science Vol. 6 (10) 26-37.

North Central Regional Farm Structures Coordinating Committee, Subcommittee on Machinery Storage and Farm Shops (1952). Farm Machinery Housing: with Suggestions for Farm Shops and Shop Equipment. North Central Regional Publication No. 31.

Paman, U., Inaba, S., Uchida, S. (2012). Power availability and Requirements for Small-Scale Rice Farm Operations: A Case in Riau Province, Indonesia. American Journal of Agricultural Science Engineering and Technology, 1(2), 2736.

Paterson, J. V. (2009). Nuffield and Leyland Tractor - Diesel engine problems - Trouble shooting. Electronic document.
Retrieved from: http://www.thenuffieldandleylandtractorclub .co.uk/wp/wp-content/themes/nuffield/images\%20two/Diesel \%20engine\%20problems.pdf. Accessed 14 March 2016.

Petrov, S., Bisnovaty, S. (1986). Repair of Farming Machinery. Mir Publishers. Moscow.

Sims, B. G. and Kienzle, J. (2006). Farm Power and Mechanization for small farms in sub-Saharan Africa. FAO Agricultural and Food Engineering Technical Report. ISSN 1814-1137.

Sullivan, G. P., Dean, J. D., Dixon, D. R. (2007). Top Operation and Maintenance, Efficiency Opportunities at DoD/Army Sites. A Guide for O\&M /Energy Managers and Practitioners, U.S.A.

Taiwo, A., Kumi, F. (2015). Status of Agricultural Mechanization in Ghana: A Case Study of Maize Producing Farmers in Ejura/Sekyedumase District, Ashanti Region. International Research Journal of Engineering and Technology Vol, 2 (9) 36-43.

University of Florida (1998). The Disaster Handbook National Edition. IFAS publication DH 617.

Utah State University Cooperative Extension (1995). The ten commandments of tractor safety. Farm Machinery Fact Sheet FM-27. Electronic document. Retrieved from: https://extension.usu.edu/files/publications/factsheet/FM27.pdf, Accessed 11 March 2016. 